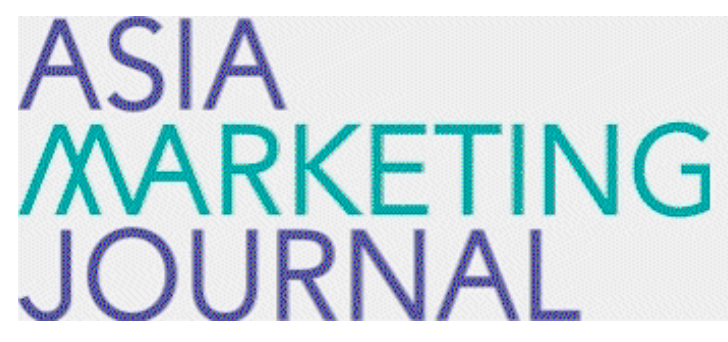

ASIA MARKETING JOURNAL

Volume 21 | Issue 4

Article 2

$1-31-2020$

\title{
The Causes of Guilt in Ready-meal Users: A Focus on Cooking Instructions and Consumers' Health Locus of Control
}

Hyunsook Shin

Dongmin Lee

Jeeyoung Lim

Moon

Follow this and additional works at: https://amj.kma.re.kr/journal

Part of the Marketing Commons

\section{Recommended Citation}

Shin, Hyunsook; Lee, Dongmin; Lim, Jeeyoung; and Moon (2020) "The Causes of Guilt in Ready-meal Users: A Focus on Cooking Instructions and Consumers' Health Locus of Control," Asia Marketing Journal: Vol. 21 : Iss. 4 , Article 2.

Available at: https://doi.org/10.15830/amj.2020.21.4.25

This Article is brought to you for free and open access by Asia Marketing Journal. It has been accepted for inclusion in Asia Marketing Journal by an authorized editor of Asia Marketing Journal. 


\title{
The Causes of Guilt in Ready-meal Users: A Focus on Cooking Instructions and Consumers' Health Locus of Control
}

\author{
Hyunsook Shin* \\ Dongmin Lee** \\ Jeeyoung Lim*** \\ Junghoon Moon****
}

Although ready meals have recently increased their market share in the Korean food industry, a literature review found that the use of ready meals triggers feelings of guilt in homemakers. Such guilt arises as a result of several factors apparently related to consumers health. Consequently, levels of guilt might be expected to vary depending on consumers' perceived health locus. The present study aims to examine (a) how health locus affects guilty feelings about ready-meal consumption, (b) how the effect varies in relation to the consumption of different types of ready meal, and (c) the relationship between consumers' guilty feelings and willingness to buy ready meals. Three dimensions of health locus of control (HLC) -internal HLC (IHLC), powerful-others HLC (PHLC), and chance HLC (CHLC) - were presumed to influence consumers' feelings of guilt in association with ready meals. Data were collected via an online survey, and participants were randomly assigned to either of two groups: one group was instructed to heat meals in a microwave (ready-to-heat [RTH] group, $\mathrm{n}=104$ ) and the other cooked using a pan with additional ingredients (ready-to-cook [RTC] group, $n=101$ ). The study found that guilty feelings about consuming RTH meals increased in line with increased external HLCs, namely, PHLC and CHLC. For the RTC group, guilt increased in line with increased PHLC. IHLC had no significant effect on guilty feelings in either group. Willingness to buy ready meals decreased for both groups as consumers' feelings of guilt increased. Even RTC meals, which require more time and energy in food preparation, did not reduce guilty feelings among consumers with higher PHLC. RTC meals are preferable for consumers with higher CHLC, since their sense of greater involvement in the cooking process alleviates their feelings of guilt. Cooking with already prepared and uncooked ingredients brought fun and joy, both for the participants and their significant others. This interpretation may be developed into a strategic plan by ready-meal producers to strengthen their marketing strategy.

Keywords: ready meals, feelings of guilt, health locus of control, willingness to buy

\footnotetext{
* Researcher, Program in Regional Information, Department of Agricultural Economics and Rural Development, College of Agriculture and Life Science, Seoul National University (hanny2@snu.ac.kr)

** Assistant Professor, Food Processing and Distribution, College of Life Science, Gangneung-Wonju National University (dongminlee@gwnu.ac.kr)

*** Researcher, Program in Regional Information, Department of Agricultural Economics and Rural Development, College of Agriculture and Life Science, Seoul National University (epicurious24@gmail.com)

**** Professor, Program in Regional Information, Department of Agricultural Economics and Rural Development, College of Agriculture and Life Science, Seoul National University (moonj@snu.ac.kr), Corresponding Author
} 


\section{Introduction}

Consumers are eating more ready meals than ever before. Several socio-economic factors have contributed to this phenomenon: increased female involvement in the workplace, the increase in single- and double-income-couple households, and a lack of guidance in traditional cooking from older generations (Costa, Schoolmeester, Dekker, \& Jongen, 2007; Geeroms, Verbeke, \& Kenhove, 2008). When it comes to food choice, consumers prioritize convenience as much as taste, nutritional value, and price (Candel, 2001; Celnik, Gillespie, \& Lean, 2012; Dave, An, Jeffery, \& Ahluwalia, 2009). Convenient ready meals are an attractive option for women for whom making time to cook seems to be yet another source of pressure.

Even though ready meals make consumers' lives easier, there are some factors that cause guilty feelings about ready-meal consumption. Convenience, which has been considered the key advantage of ready meals, may trigger guilt because the use of ready meals can be perceived as neglecting one's duty to invest time and effort in meal preparation (Olsen, Sijtsena, \& Hall, 2010). In addition, the method of preparing ready-to-heat (RTH) meals may be a guilt-arousing factor for consumers who are good cooks, since they do not have the option of adding extra ingredients. The majority of RTH meals are heated using a microwave, which limits the creation of new dishes. Horning et al. (2017) also noticed that ready meals lack fruit and vegetables relative to homemade meals.

In addition, the unbalanced nutritional properties of ready meals, which are often high in sodium and calories, can lead to the perception that ready meals in general are unhealthy (Costa et al., 2003). Many studies have examined the impact of ready meals on health. Frequent consumption of ready meals can cause weight gain (Van der Horst, Brunner, \& Siegrist, 2011) and chronic diseases such as cardiovascular disease, diabetes, and cancer (Celnik, Gillespie, \& Lean, 2012; Jabs \& Devine, 2006) because of the high energy, fat, salt, and sugar levels that ready meals possess (Anderson et al., 2008; Gibson, Armstrong, \& McIlveen, 2000; Van der Horst, Brunner, \& Siegrist, 2011).

Despite the problems with ready meals, their market share is increasing in the Republic of Korea. According to Korea's Ministry of Agriculture, Food, and Rural Affairs, the domestic ready-meal market has increased from 2.4 trillion dollars in 2014 to 3.5 trillion dollars in 2017 (Lee, Lee, \& Jung., 2018) and is expected to have increased by $34.3 \%$ by 2035 (Park, Kwon, \& Nah, 2019). Given the growing economic importance of the ready-meal market in Korea, a better understanding of it is needed to predict the purchasing factors of ready meals.

According to many studies, health has been identified as a motivator in food choice behavior (Contento, Michela, \& Goldberg, 1988; Roininen 
et al., 2001; Roininen, Lahteenmaki, \& Tuorila, 1999; Schifferstein \& Oude Ophuis, 1998). Olsen, Sijtsema, and Hall (2010) have investigated the effect of moral attitudes on ready-meal consumption; Geeroms, Verbeke, and Kenhove (2008) explored the association between healthrelated motive orientations and ready-meal consumption; and Bennett et al. (1994) used the health locus of control (HLC) to measure individual food consumption and eating patterns.

However, HLC's effects on the willingness to buy ready meals remains underexplored. HLC refers to the belief that one's health quality is a result of one's own behavior or other factors, such as the influence of others or luck (Wallston \& Wallston, 1978b). It has been used to predict health-related behaviors such as adolescent smoking (Eiser et al., 1989), tobacco and drinking consumption in adults (Calnan, 1989; Winefield et al., 1989), the success of people trying to quit smoking (Segall \& Wynd, 1990), engagement in physical activity (Calnan, 1989; Carlson \& Petti, 1989), and adolescent substance abuse (Dielman et al., 1987). In light of these studies, this paper examines how HLC affects willingness to buy ready meals, which might incur different levels of guilty feelings, focusing on Korean consumers.

The study aims to expand the limited literature on ready meals by introducing health-related variables that are assumed to influence the feelings of guilt experienced by consumers. It compares the feelings of guilt that are triggered by the consumption of different types of ready meal, based on consumers' HLC. Understanding the implications of health perceptions can contribute to the development of the concept for different types of ready meal.

\section{Empirical Study}

\subsection{Major Constructs}

\subsubsection{Health locus of control (HLC).}

"Locus of control" is a term that has its origins in Rotter's (1966) social learning theory. It has been widely used as a main construct in behavioral research. This construct has been used to predict specific health-related behaviors (Armitage, Norman, \& Conner, 2002; Rotter, 1954, 1972; Wallston \& Wallston, 1978a). Health behaviors are associated with lifestyle and include exercise, smoking habits, alcohol consumption, and dietary habits (Norman et al., 1998).

The HLC construct holds that a behavior may be derived either from factors within the individual's control (internal) or out of their control (external). Levenson (1974) insisted that external loci of control can be divided into two subscales: control by powerful others (PHLC), such as family members or doctors, and chance events (CHLC), viewed as arising 
from fate or luck. People with a higher internal HLC (IHLC) can be expected to have higher levels of self-control. Thus, higher levels of self-control are associated with healthier food choices and lower consumption of high-fat foods (Turner et al., 2010).

Wallston, Wallston, Kaplan, and Maides (1976) developed this construct into a multidimensional health locus of control scale. They argued that the HLC scale measures the extent to which an individual's health is determined by their behavior. The IHLC scale indicates the extent to which people believe themselves to be responsible for their own health. Wallston (1991) observed that health-related behavior is more likely to be exhibited by people who cherish their health more (also called health value). With regard to the subscales of external HLC (EHLC), people with higher PHLC readily follow the advice given to them by medical professionals, whereas those with lower PHLC are indifferent to their health, since their strong belief in medical technology causes them to deprioritize caring for their bodies; those with high CHLC believe that whether they are healthy or unhealthy is beyond their control (Wallston \& Wallston, 1978b).

Considering that health is an important factor in consumers' food consumption practices (Contento, Michela, \& Goldberg, 1988; Geeroms, Verbeke, \& Kenhove, 2008; Roininen et al., 2001; Roininen, Lahteenmaki, \& Tuorila, 1999; Schifferstein \& Oude Ophuis, 1998), HLC could be a predictor of consumers' willingness to buy ready meals; whether they are happy to use ready meals may be analyzed with HLC. Three aspects of HLC are indicated in Table 2, each of which comprises six survey items. Each HLC is expected to have a different effect on feelings of guilt, depending on the type of ready meal. Figure 1 below describes the research model of this study.

\subsubsection{Feelings of guilt.}

Guilt, which causes people to dwell on their actions, leads to confession and compensation. According to Perlman (1958), guilt is a result of conflict between the ego and the superego. In other words, individuals feel guilt when they believe that their behavior or their intention to do something is at odds with their conscience. Thus, guilt has been identified as a moral emotion linked to the comfort and welfare of other people or society (Eisenberg, 2000; Skoe et al., 2002; Steenhaut \& Van Kenhove, 2005). The emotion of guilt has been used in previous consumer behavior research. Dahl et al. (2003) stated that guilt can arise from the use of products that are harmful to one's health, extending to the purchase of foreign products and disposal of recyclable products. Marks and Mayo (1991) noted that people feel guilt when they choose an inappropriate alternative. Strutton et al. (1994) studied the impact of guilt on the probability of engaging in an unethical activity. 
Steenhaut and Van Kenhove (2005) found that people weigh opportunistic drives and guilty feelings in ethically questionable situations.

Costa et al. (2007) discovered that moral attitudes, including saving time and energy in preparing meals, play a great role in consuming meals. While homemade meals are regarded positively, ready meals are related to negative feelings such as guilt, regret, and neglect of one's duty to cook (Costa et al., 2007). Consequently, consumers are susceptible to morally based criticism when replacing homemade meals with ready meals.

With regard to the guilt associated with HLC, people with a higher IHLC would feel more guilt in consuming RTH meals since they are likely to engage in healthier behavior (Wallston, 1991). By contrast, their guilt may decrease when consuming ready-to-cook (RTC) meals because they can modify the recipe to make it better for their health. People with a higher PHLC would feel more guilt in consuming any type of ready meal since they would not want to provide significant others with ready meals, given that doctors purportedly do not recommend them. People with a higher CHLC do not care what they eat because of the belief that their health is out of their control, so they would feel less guilt in consuming any type of ready meal.

Benton, Greenfield, and Morgan (1998) used two types of survey item to examine the negative emotions experienced as a result of consuming chocolate. Guilt was measured through a factor analysis using a principal component analysis and varimax rotation. Of the 12 survey items, only 4, whose factors were higher than 0.6 , were used in the present survey. Those items were modified for the purpose of measuring feelings of guilt provoked by the consumption of ready meals: (1) After eating ready meals, I often wish I had not; (2) I feel guilty after eating ready meals; (3) I feel depressed and dissatisfied with life after eating ready meals; and (4) I feel unhealthy after I have eaten ready meals.

\subsubsection{Willingness to buy.}

Mai and Hoffmann (2015) measured how consumers' health consciousness and food flavors influence purchase intention. Three measurements were modified to examine consumers' willingness to purchase ready meals: (1) I will buy this product; (2) Next time I am buying a ready meal, I will choose this product; and (3) I prefer this product to other ready meals. A five-point Likert scale was used: $1=$ totally disagree, $2=$ partly disagree, $3=$ indifferent, $4=$ partly agree, and $5=$ totally agree. Feelings of guilt are assumed to affect willingness to buy, leading to the following hypotheses: 


\subsection{Hypotheses $^{1)}$}

H1a: As consumers' IHLC increases, their feelings of guilt increase when they have RTH meals.

H1b: As consumers' PHLC increases, their feelings of guilt increase when they have RTH meals.

H1c: As consumers' CHLC increases, their feelings of guilt decrease when they have RTH meals.

H1d: Consumers' willingness to buy RTH meals will decrease as their feelings of guilt at consumption increase.

H2a: As consumers' IHLC increases, their feelings of guilt will decrease when they have RTC meals.

H2b: As consumers' PHLC increases, their feelings of guilt will increase when they have RTC meals.

H2c: As consumers' CHLC increases, their feelings of guilt will decrease when they have RTC meals.

H2d: Consumers' willingness to buy RTC meals will decrease as their feelings of guilt at consumption increase.

\section{Method}

Ready meals are defined as fully or partially prepared food that requires additional preparation time, cooking skills, and energy in terms of food processing and distribution, along with fast food and ready-to-eat takeaway foods (Celnik, Gillespie, \& Lean, 2012). According to Costa, Dekker, Beumer, Rombouts, and Jongen (2001), ready meals are classified into four types: RTH and RTC, as described above, and ready-to-eat (RTE) and ready-to-endcook (RTEC). Such ready meals are classified according to their degree of cooking preparation. RTE meals are defined as processed foods that can be eaten immediately without additional preparation, whereas RTH meals, such as frozen pizza, require heating for 15 minutes before consumption. RTEC meals, such as dehydrated pasta dishes, often need longer preparation times than RTH meals do. RTC meals require complete cooking of some or all of their components.

While there are many varieties of ready meal, previous studies distinguishing between these types are scarce. Moreover, the associated feelings of guilt may be expected to differ according to the ready meal's preparation

1) Unlike marketing research, which emphasizes theoretical explanations in general, the hypothesis development of this paper appears to be unique from an academic marketing perspective as a result of cultural differences, meaning that, in the domain of this paper, fast-emerging concepts are welcomed, as are fast empirical analyses. We appreciate the openness of the editor-in-chief in this respect. 
method. Consequently, RTH ready meals, which require little involvement on the part of consumers, and RTC ready meals, which require considerable time and caution to prepare, were used in this study. RTH ready meals were considered to comprise meals that were heated by microwave, while RTC ready meals were cooked using a pan with the addition of extra ingredients.

An online survey was conducted in which 377 respondents participated, randomly divided into two different groups of 186 and 191 respondents. Table 1 below shows demographic information for the participants. Participants were given a scenario in which they were shopping in a mall and considering the purchase of frozen fried rice for a family supper. Each group was instructed to read different cooking instructions. One group read cooking instructions that described the preparation of ready meals using a microwave and three steps: placing the food in a bowl capable of being microwaved, wrapping the bowl to prevent dehydration, and microwaving for 3 to 4 minutes, depending on the microwave's performance. The other group was instructed to use a pan according to three steps: placing one tablespoon of olive oil in the pan over a low heat; increasing the heat to medium, placing the ready meal in the pan, and frying it for around 3 to 4 minutes; and adding extra ingredients as desired. All participants were Korean married women ranging in age from their 20s to their 60s, and all were asked to fill in a questionnaire anonymously. It was mandatory that they answer all questions before submitting the questionnaire.

The data were analyzed through a partial least square (PLS) regression using SmartPLS software for PLS structural equation modeling (Wong, 2013). Since this study is focused on participants who had purchased ready meals within the past month, only 104 and 101 responses from each respective group were used. The respondents' age, number of dependent children, monthly household income, and monthly groceries expenditure were considered as control variables in the analysis.

Before analyzing the data with the PLS method, the data's validity and reliability were tested. The validity was tested for convergent and discriminant validity, while the reliability was tested for Cronbach's alpha and composite reliability. The rule of thumb for convergent validity is (a) factor loading $>0.7$, (b) communality $>0.5$, and (c) average variance extracted (AVE) >0.5 (Latan \& Ghozali, 2012; Yana, Rusdhi, \& Wibowo, 2015). Survey parameters that exceeded a factor loading of 0.7 remained for these standards, as shown in Appendices A and B. 
〈Table 1〉 Demographic Characteristics of the Participants

\begin{tabular}{|c|c|c|}
\hline & RTH meals group $(n=104)$ & RTC meals group $(n=101)$ \\
\hline \multicolumn{3}{|l|}{ Age } \\
\hline $20-29$ & 12 & 8 \\
\hline $30-39$ & 18 & 22 \\
\hline $40-49$ & 29 & 36 \\
\hline $50-59$ & 33 & 28 \\
\hline $60-69$ & 12 & 7 \\
\hline \multicolumn{3}{|l|}{ Residence } \\
\hline Seoul & 34 & 40 \\
\hline Pusan & 0 & 4 \\
\hline Dague & 4 & 3 \\
\hline Incheon & 9 & 5 \\
\hline Gwangju & 3 & 0 \\
\hline Daejeon & 3 & 2 \\
\hline Ulsan & 0 & 3 \\
\hline Gyeonggi-do & 32 & 30 \\
\hline Gangwon-do & 3 & 2 \\
\hline Chungchengbuk-do & 1 & 1 \\
\hline Chungchengnam-do & 1 & 3 \\
\hline Jeollabuk-do & 5 & 2 \\
\hline Jeollanam-do & 1 & 2 \\
\hline Gyeongsangbuk-do & 3 & 2 \\
\hline Gyeongsangnam-do & 4 & 2 \\
\hline Jeju & 1 & 0 \\
\hline \multicolumn{3}{|l|}{ Number of children } \\
\hline 0 & 19 & 20 \\
\hline 1 & 25 & 25 \\
\hline 2 & 52 & 50 \\
\hline 3 & 8 & 6 \\
\hline \multicolumn{3}{|c|}{ Monthly groceries expenditure } \\
\hline$\$ 0-\$ 850$ & 75 & 72 \\
\hline$\$ 851-\$ 1,700$ & 24 & 22 \\
\hline$\$ 1,701-\$ 2,600$ & 3 & 2 \\
\hline$\$ 2,601-\$ 3,400$ & 1 & 2 \\
\hline$\$ 3,401-\$ 4,200$ & 1 & 1 \\
\hline$\$ 4,201$ and above & 0 & 2 \\
\hline
\end{tabular}


〈Figure 1〉 Research model

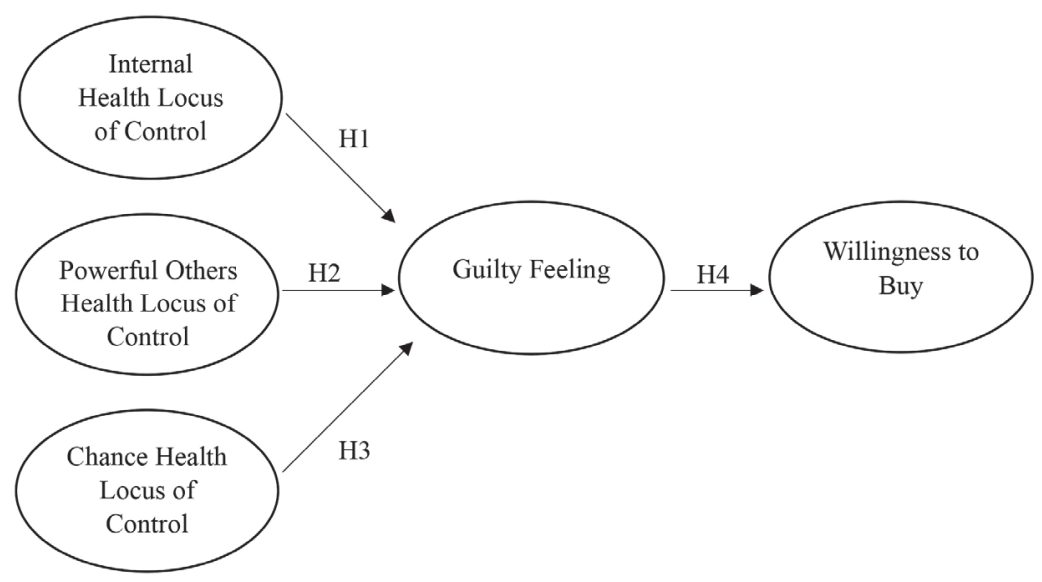

〈Table 2〉 Measurement Instruments

\begin{tabular}{cl}
\hline Items & \multicolumn{1}{c}{ Measures } \\
\hline IHLC1 & If I become sick, I have the power to make myself well again. \\
\hline IHLC2 & I am directly responsible for my health. \\
\hline IHLC3 & Whatever goes wrong with my health is my own fault. \\
\hline IHLC4 & My physical well-being depends on how well I take care of myself. \\
\hline IHLC5 & When I fall ill, I know it is because I have not been taking care of myself properly. \\
\hline IHLC6 & I can pretty much stay healthy by taking good care of myself. \\
\hline PHLC1 & If I see an excellent doctor regularly, I am less likely to have health problems. \\
\hline PHLC2 & I can only maintain my health by consulting health professionals. \\
\hline PHLC3 & Other people play a big part in whether I stay healthy or become sick. \\
\hline PHLC4 & Health professionals keep me healthy. \\
\hline PHLC5 & The type of care I receive from other people is responsible for how well I recover from an illness. \\
\hline PHLC6 & Following doctors' orders to the letter is the best way for me to stay healthy. \\
\hline CHLC1 & I often feel that no matter what I do, if I am going to get sick, I will get sick. \\
\hline CHLC2 & It seems that my health is greatly influenced by accidental events. \\
\hline CHLC3 & When I am sick, I just have to let nature take its course. \\
\hline CHLC4 & When I stay healthy, I'm just plain lucky. \\
\hline CHLC5 & Even when I take care of myself, it is easy to get sick. \\
\hline CHLC6 & When I become ill, it is a matter of fate. \\
\hline GF1 & After eating ready meals, I often wish I had not. \\
\hline GF2 & I feel guilty after eating ready meals. \\
\hline GF3 & I feel depressed and dissatisfied with life after eating ready meals. \\
\hline GF4 & I feel unhealthy after I have eaten ready meals. \\
\hline WTB1 & I will buy this product. \\
\hline WTB2 & Next time I am buying a ready meal, I will choose this product. \\
\hline WTB3 & I prefer this product to other types of ready meal. \\
\hline
\end{tabular}




\section{Analyses and Results}

As shown in Table 5, feelings of guilt decreased for the group of RTH meals as respondents IHLC increased. However, the result was not statistically significant $(\beta=-0.134$, $\mathrm{p}=0.072$ ) and Hypothesis 1a is not supported. Because consumers believed themselves to have control over their own health, feelings of guilt over using RTH meals were reduced.

By contrast, feelings of guilt increased as consumers' PHLC increased in relation to the consumption of RTH meals $(\beta=0.199, p=$ 0.005), supporting Hypothesis 1b. Because these consumers rely on medical treatment to remain healthy, their feelings of guilt increased as a result of consuming RTH meals. This means consumers who depend on their physicians or who care about their significant others experience guilt when they consume RTH meals.

Contrary to expectations regarding Hypothesis 1c, the higher consumers' CHLC was, the greater their feelings of guilt in the RTH meals group $(\beta=0.327, p=0.000)$. Even though consumers believed that being healthy is a matter of fate and thus out of their control, the guilt experienced when using RTH meals increased.

In the RTC meals group, consumers' guilty feelings decreased $(\beta=-0.149, p=0.127)$ as their IHLC increased. Hypothesis 2a was not supported, however, because their feelings of guilt were not statistically significant. Even though people felt that they were responsible for their own health, their guilty feelings decreased, regardless of the type of ready meal.

In the RTC meals groups, as consumers' PHLC increased, so too did their guilty feelings, with a statistical significance $(\beta=0.338, p=$ 0.000) supporting Hypothesis 2b. Because people value their family members and are likely to listen to medical information, their feelings of guilt increased when consuming RTC meals.

〈Table 3〉 Correlation of Latent Variables of the RTH Meals Group

\begin{tabular}{cccccccccc}
\hline & CHLC & GF & IHLC & PHLC & WTB & Age & Child & Grocery & Income \\
\hline CHLC & 1 & 0 & 0 & 0 & 0 & 0 & 0 & 0 & 0 \\
\hline GF & 0.407 & 1 & 0 & 0 & 0 & 0 & 0 & 0 & 0 \\
\hline IHLC & -0.300 & -0.257 & 1 & 0 & 0 & 0 & 0 & 0 & 0 \\
\hline PHLC & 0.202 & 0.282 & -0.126 & 1 & 0 & 0 & 0 & 0 & 0 \\
\hline WTB & -0.138 & -0.507 & 0.209 & 0.014 & 1 & 0 & 0 & 0 & 0 \\
\hline Age & -0.133 & 0.155 & -0.013 & 0.102 & -0.013 & 1 & 0 & 0 & 0 \\
\hline Child & -0.126 & -0.068 & -0.065 & 0.047 & 0.190 & 0.508 & 1 & 0 & 0 \\
\hline grocery & 0.154 & 0.202 & -0.076 & 0.159 & 0.034 & -0.158 & 0.083 & 1 & 0 \\
\hline income & -0.113 & -0.080 & -0.040 & -0.018 & -0.031 & -0.035 & 0.176 & 0.243 & 1 \\
\hline
\end{tabular}


Hypothesis 2c was not supported. Although consumers' feelings of guilt increased as their level of CHLC increased when consuming RTC meals, the guilt experienced was not significant $(\beta=0.086, p=0.167)$. Even though people believed that their health was out of their control, their guilty feelings at consuming RTC meals increased. It is difficult to generalize from this result, however, because of the statistical value.
Consumers' willingness to buy ready meals decreased in both the RTH $(\beta=-0.544, p=$ $0.000)$ and $\operatorname{RTC}(\beta=-0.460, p=0.000)$ meals groups as their guilt at consuming ready meals increased. Given these results, Hypotheses $1 \mathrm{~d}$ and $2 \mathrm{~d}$ are supported.

With regard to the control variables, only income had a significant effect on willingness to buy RTH ready meals $(\beta=-0.142, p=0.023)$.

〈Table 4 Correlation of Latent Variables of the RTC Meals Group

\begin{tabular}{cccccccccc}
\hline & CHLC & GF & IHLC & PHLC & WTB & Age & Child & Grocery & Income \\
\hline CHLC & 1 & 0 & 0 & 0 & 0 & 0 & 0 & 0 & 0 \\
\hline GF & 0.246 & 1 & 0 & 0 & 0 & 0 & 0 & 0 & 0 \\
\hline IHLC & 0.123 & -0.054 & 1 & 0 & 0 & 0 & 0 & 0 & 0 \\
\hline PHLC & 0.529 & 0.345 & 0.251 & 1 & 0 & 0 & 0 & 0 & 0 \\
\hline WTB & 0.140 & -0.457 & 0.079 & 0.057 & 1 & 0 & 0 & 0 & 0 \\
\hline Age & 0.197 & -0.003 & 0.208 & 0.199 & 0.104 & 1 & 0 & 0 & 0 \\
\hline Child & 0.188 & 0.076 & 0.009 & 0.063 & 0.109 & 0.520 & 1 & 0 & 0 \\
\hline Grocery & -0.038 & 0.099 & -0.057 & 0.089 & -0.144 & -0.182 & 0.046 & 1 & 0 \\
\hline Income & 0.015 & -0.033 & 0.070 & 0.003 & -0.060 & 0.051 & 0.040 & 0.056 & 1 \\
\hline
\end{tabular}

$\langle$ Table 5〉 Results of Structural Model

\begin{tabular}{ccccc}
\hline & \multicolumn{2}{c}{ RTH meals group } & \multicolumn{2}{c}{ RTC meals group } \\
\hline & Path coefficients & P-value & Path coefficients & P-value \\
\hline $\mathrm{IHLC} \rightarrow$ GF & -0.134 & 0.072 & -0.149 & 0.127 \\
\hline $\mathrm{PHLC} \rightarrow$ GF & 0.199 & 0.005 & 0.338 & 0.000 \\
\hline $\mathrm{CHLC} \rightarrow$ GF & 0.327 & 0.000 & 0.086 & 0.167 \\
\hline $\mathrm{GF} \rightarrow$ WTB & -0.544 & 0.000 & -0.460 & 0.000 \\
\hline age $\rightarrow$ WTB & 0.013 & 0.449 & 0.013 & 0.446 \\
\hline child $\rightarrow$ WTB & 0.158 & 0.062 & 0.145 & 0.072 \\
\hline grocery $\rightarrow$ WTB & 0.167 & 0.027 & -0.099 & 0.062 \\
\hline income $\rightarrow$ WTB & -0.142 & 0.023 & -0.077 & 0.208 \\
\hline $\mathrm{R}^{2}$ & 0.316 & & 0.246 & \\
\hline
\end{tabular}


Age, number of dependent children, and monthly groceries expenditure had a positive effect on willingness to buy, but none of these had any significance in either group. As consumers' income increases, their willingness to buy RTH ready meals decreases. Overall, there was no significant difference between the two groups in relation to willingness to buy.

\section{Discussion}

Given that health is an important factor affecting consumers' food consumption practices (Contento, Michela, \& Goldberg, 1988: Geeroms, Verbeke, \& Kenhove, 2008; Roininen et al., 2001; Roininen, Lahteenmaki, \& Tuorila, 1999; Schifferstein \& Oude Ophuis, 1998), the present research studied how each HLC affects guilty feelings from consuming different types of ready meal, which ultimately affects willingness to buy ready meals.

Before discussing the results, it is crucial to consider the difference in preparation times required for RTH and RTC meals. There have been very few studies regarding preparation times for different types of ready meal, but it is commonly thought that RTC meals require more preparation time than $\mathrm{RTH}$ meals do. Consumers who use RTH meals may place the package into a microwave oven or pour the contents into a dish, in accordance with the instructions, in a process that takes under five minutes. By contrast, RTC meals must be prepared from scratch, although all the packaged ingredients are processed. Occasionally, consumers may modify the recipe by adding other ingredients, indicating that RTC ready meals require more care and time to prepare.

The results presented in Table 5 illustrate that CHLC has a positive effect on feelings of guilt only in relation to RTH meals. Consumers with higher CHLC think that being cheerful is an important health-related motivation. These individuals control their health altruistically since they desire "good social contacts" and "harmony with oneself and others" (Geeroms, Verbeke, \& Kenhove, 2008). For them, RTH meals cannot satisfy their needs, since there is no scope to invest greater time and effort in the meal when using a microwave. A reduction in cooking time seems undesirable for them, since it may give the impression that they are neglecting their duty toward their significant others. Thus, ready-meal consumption can induce negative feelings like guilt for consumers who have a strong sense of social responsibility (Geeroms, Verbeke, \& Kenhove, 2008).

PHLC had a positive effect on guilty feelings in consuming both RTH and RTC meals. Consumers with a higher PHLC consider health to be a social responsibility (Geeroms, Verbeke, \& Kenhove, 2008). People with higher EHLC perceive health as an extension of social activity. However, one of the features of PHLC that 
distinguishes it from CHLC is that it causes a greater desire to be healthy (Wallston \& Wallston, 1978b). Although both segments are classified as EHLC, a higher PHLC is associated with greater concern about one's health than a higher CHLC. Even RTC meals may arouse feelings of guilt, since the meals' preparation is seemingly effortless and offers little opportunity to impress others. Furthermore, these consumers may also believe that ready meals are not good for their health, regardless of the meal type.

It is noteworthy that IHLC had no significant effect for either group. Consumers with higher IHLC regard health as an individualistic responsibility (Geeroms, Verbeke, \& Kenhove, 2008). Maintaining their bodies and staying slim are important sources of motivation in their lives. They may place greater emphasis on their private lives than on socializing with other people. Using a microwave to prepare a meal may be less associated with feelings of guilt because these individuals are not obliged to invest time and energy in serving others. Thus, the belief that the maintenance of one's health is an individualistic concern can engender a more positive attitude toward ready meals. The consumption of RTH ready meals does not necessarily mean that those consuming them do not care about their health. Rather, consumers who live hectic lives simply opt for greater efficiency. Rational consumers with limited resources - little time and poor cooking skills - make the optimal choice to minimize opportunity cost.

Food consumption works as a tool to achieve and maintain a healthy life and is imbued with high levels of social and cultural value. (Costa et al., 2003; Roininen, Lahteenmaki, \& Tuorila, 1999). Therefore, no food consumption process should be a burden for consumers. The consumption of ready meals may or may not be a rational choice, depending on how consumers perceive their HLC and social relationships.

\section{Implications}

\subsection{Theoretical Implications}

HLC has been commonly used as a predictor of health-related behavior in social learning theory (Rotter, 1966). Unlike studies in which only health-related behavior variables were used, the present paper includes feelings of guilt to test for variation in relation to HLC. Moreover, because the consumption of ready meals may be associated with feelings of guilt, it is thus worth exploring the relationship between HLC and such feelings when trying to understand the relationship between health and ready-meal consumption. Even though Bennett et al. (1994) examined broad food consumption and the eating behavior of consumers, research focused on ready-meal consumption is rare. Given this fact, the present paper is 
expected to broaden the body of knowledge in social learning theory.

\subsection{Managerial Implications}

The findings from this study also provide managerial implications for the Korean readymeal market. People with a higher IHLC may or may not purchase ready meals since guilty feelings decreased without statistical significance in relation to both ready-meal groups. Thus, there is a risk in developing ready meals for these consumers. Similarly, managers in the food business are unlikely to target consumers who have a higher PHLC, that is, people who are not likely to cook ready meals for their significant others because they care more about their family members and trust medical information more. Further studies could examine whether adding extra vegetables and fruits, which are hardly found in ready meals (Horning et al., 2017), could reduce their guilty feelings. People with a higher CHLC would be appropriate target customers, especially in the RTC meals market. The opportunity to demonstrate their care for others contributes to the creation of strong bonds and increases their confidence and self-efficacy in cooking. Supporting consumers in the discovery of their interest in and talent for cooking may help to decrease their sense of guilt, leading to their greater willingness to buy. However, identifying which consumers have which type of HLC in various markets needs to be investigated before any practical application is possible.

〈Received September 10. 2019〉

〈Accepted January 31. 2020〉

\section{References}

AbuSabha, R., \& Achterberg, C. (1997). Review of self-efficacy and locus of control for nutrition-and health-related behavior. Journal of the American Dietetic Association, 97 (10), 1122-1132.

Anderson, A., Wrieden, W., Tasker, S. et al. (2008). Ready meals and nutrient standards: challenges and opportunities. Proc Nutr Soc 67, E223.

Armitage, C. J., Norman, P., \& Conner, M. (2002). Can the theory of planned behavior mediate the effects of age, gender and multidimensional health locus of control?. British Journal of Health Psychology, 7 (3), 299-316.

Bennett, P. Moore, L., Smith, A., Murphy, S., \& Smith, C. (1994). Health locus of control and value for health as predictors of dietary behavior. Psychology and Health, 10(1), 41-54.

Benton, D., Greenfield, K., \& Morgan, M. (1998). The development of the attitudes to chocolate questionnaire. Personality and Individual Differences, 24(4), 513-520. 
Beshara, M., Hutchinson, A., \& Wilson, C. (2010). Preparing meals under time stress. The Experience of Working Mothers. Appetite, 55, 695-700.

Calnan M. (1989) Control over health and patterns of health related behaviour. Social Science and Medicine, 29, 131-136.

Candel, M. J. (2001). Consumers' convenience orientation towards meal preparation: conceptualization and measurement. Appetite, 36(1), 15-28.

Carlson B. R. and Petti K. (1989) Health Locus of Control and participation in physical activity. American Journal of Health Promotion, 3, 32-37.

Celnik, D., Gillespie, L., \& Lean, M. E. J. (2012). Time-scarcity, ready-meals, ill-health and the obesity epidemic. Trends in Food Science \& Technology, 27, 4-11.

Cho, Y., Kim, N., Lee, M. M., Lim, J. H., Han, H. \& Park, H. Y. (2015). South Korean women leaders' struggles for a work and family balance. Human Resource Development International, 18(5), 521-537.

Contento, I. R., Michela, J. L., \& Goldberg, C. J. (1988). Food choice among adolescents: Population segmentation by motivations. Journal of Nutrition Education, 20(6), 289298.

Costa, A. I. A., Dekker, M., Beumer, R. R., Rombouts, F. M., \& Jongen, W. M. F. (2001). A consumer-oriented classification system for home meal replacements. Food
Quality and Preference, 12, 229-242.

Costa, A. I. A., Schoolmeester, D., Dekker, M., \& Jongen, W.M.F. (2003). Exploring the use of consumer collages in product design. Trends in Food Science \& Technology, 14, 17-31.

Costa, A. I. A., Schoolmeester, D., Dekker, M., \& Jongen, W.M.F. (2007). To cook or not to cook: A means-end study of motives for choice meal solutions. Food Quality and Preference, 18, 77-88.

Dahl, D. W., H. Honea and R. V. Manchanda. (2003). The Nature of Self-Reported Guilt in Consumption Contexts, Marketing Letters, 14(3), 159-171.

Daniels, S., Glorieux, I., Minnen, J., \& Tienoven, T. P. (2012). More than preparing a meal? Concerning the meanings of home cooking. Appetite, 58, 1050-1056.

Dave, J. M., An, L. C., Jeffery, R. W., \& Ahluwalia, J. S. (2009). Relationship of attitudes toward fast food and frequency of fast food intake in adults. Obesity, 17 (6), 1164-1170.

Dielman T.E., Campanelli P.C., Shope J.T. and Butchart A.T. (1987) Susceptibility to peer pressure, self- esteem, and health locus of control as correlates of adolescent substance abuse. Health Education Ouarterly, 14, 207-221.

Douthitt, Robin A., Kim, S. (2006). The Effects of Mothers' Market Work Participation and Away-from-Home Food Consumption 
on Children's Selected Nutrient Intakes. International Journal of Human Ecology, 7(2), December 2006. 63-74.

Eisenberg, N. (2000). Emotion, Regulation, and Moral, Development, Annual Review of Psychology, 51, 665-697.

Eiser J.R., Eiser C., Gammage P. and Morgan M. (1989). Health Locus of Control and Health Beliefs in relation to adolescent smoking. British Journal of Addiction, 84, 1059-1065.

Gaignaire, A., Politzer, N. et al. (2011). "The study of effect evaluation of Classes du Goût on food consumption," a final report «EVALUATION des EFFETS des CLASSES DU GOUT》, Ministère de l' Agriculture, de l'Agroalimentaire et de la Forêt (MAAF).

Geeroms, N., Verbeke, W., \& Kenhove, P. V. (2008). Consumers' health-related motive orientations and ready meal consumption behavior. Appetite, 51, 704-712.

Gibson, J, Armstrong, G. \& Mcllveen, H. (2000). A case for reducing salt in processed foods. Nutr Food Sci 30, 167-173.

Horning, M. L., Fulkerson, J. A., Friend, S. E., \& Story, M. (2017). Reasons Parents Buy Prepackaged, Processed Meals: It Is More Complicated Than "I Don't Have Time". Journal of Nutrition Education and Behavior, 49, 60-66.

Horst, K., Brunner, T. A., \& Siegrist, M. (2010). Ready-meal consumption: associations with weight status and cooking skills. Public Health Nutrition, 14(2), 239-245. Jabs, J., \& Devine, C. M. (2006). Time scarcity and food choices: An overview. Appetite, 47, 196-204.

Latan, H. and Ghozali, I. (2012). Partial Least Square Konsep, Teknik dan Aplikasi Menggunakan Program SmartPLS 2.0 M3. Semarang: Badan Penerbit Universitas Diponegoro.

Lee, K., Um, C. C., \& Kim, S. (2004). Multiple Roles of Married Korean Women: Effect on Depression. Springer Science + Business Media, Inc, Sex Roles, Vol.51, Nos. 7/8, 469-478.

Lee, S., Lee, K., \& Jung, H. (2018). The health directionality and cooking convenience of HMR products and the effect of product quality on customer satisfaction and purchasing behavior. International Journal of Tourism and Hospitality Research, 32 (11), 169-181.

Levenson, H. (1974). Activism and powerful others: distinctions within the concept of internal-external control. J Pers Assess, 38, 377-383.

Mai, R., \& Hoffman, S. (2015). How to Combat the Unhealthy $=$ Tasty Intuition: The Influencing Role of Health Consciousness. Journal of Public Policy \& Marketing, 34(1), 63-83.

Marks, L. J. and M. A. Mayo. (1991). An Empirical Test of a Model of Consumer 
Ethical Dilemmas, Advances in Consumer Research, 18, 720-728.

Norman, P., Bennett, P., Smith, C., \& Murphy, S. (1998). Health Locus of Control and Health Behaviour. Journal of Health Psychology, 3(2), 171-180.

Olsen, N. V., Sijtsema, S. J., \& Hall, G. (2010). Predicting consumers' intention to consume ready-to-eat meals. The role of moral attitude. Appetite, 55, 534-539.

Park Min-Hee, Kwon Mahn-Woo, Nah Ken. (2019). Study on Repurchase Intention of RTP HMR Products: Focused on Meal kit. Journal of Korean Conference, 15(2), 548-557.

Perlman M. (1958). An Investigation of Anxiety as Related to Guilt and Shame. AMA Arch NeurPsych, 80(6), 752-759.

Roininen, K., Lahteenmaki, L., \& Tuorila, H. (1999). Quantification of consumer attitudes to health and hedonic characteristics of foods. Appetite, 33, 71-88.

Roininen, K., Tuorila, H., Zandstra, E. H., de Graaf, C., Vehkalahti, K., Stubenitsky, K., \& Mela, D. J. (2001). Differences in health and taste attitudes and reported behaviour among Finnish, Dutch and British consumers: A cross-national validation of the health and taste attitude scale. Appetite, 37, 33-45.

Rotter, J.B. (1954). Social Learning and Clinical Psychology. Englewood Cliffs, NJ, PrenticeHall.
Rotter, J. B. (1966). Generalized expectancies for internal and external control of reinforcement. Psychological Monographs: General and Applied, 80 (whole no.609), 1-28.

Rotter, J.B. (1972). Chance J, Phares EJ: Applications of a Social Learning Theory of Personality. New York, Holt, Rinehart \& Winston.

Schifferstein, H. N. J., \& Oude Ophuis, P. A. M. (1998). Health-related determinants of organic food consumption in the Netherlands. Food Quality and Preference, 9(3), 119-133.

Segall ME. and Wynd C.A. (1990). Health conception, Health Locus of Control, and Power as predictors of smoking behavior change. American Journal of Health Promotion, 4, 338-344.

Skoe, E. E. A., N. Eisenberg and A. Cumberland. (2002). The Role of Reported Emotion in Real-Life and Hypothetical Moral Dilemmas, Personality and Social Psychology Bulletin, 28(2), 962-973.

Steenhaut, S. \& Van Kenhove, P. (2005). Relationship Commitment and Ethical Consumer Behavior in a Retail Setting: The Case of Receiving Too Much Change at the Checkout, Journal of Business Ethics, 56, 335-353.

Strutton, D., S. J. Vitell and L. E. Pelton. (1994). How Consumers may Justify Inappropriate Behavior in Market Settings: An Application 
on the Techniques of Neutralization, Journal of Business Research, 30, 253-260.

Troye, S. V., \& Supphellen, M. (2012). Consumer Participation in coproduction: "I Made It Myself" Effects on Consumers' Sensory Perceptions and Evaluations of Outcome and Input Product. Journal of Marketing, 76, 33-46.

Turner, S.A., Luszczynska, A., Warner, L., \& Schwarzer, R. (2010). Emotional eating and uncontrolled eating styles and chocolate chip cookie consumption. A controlled trial of the effects of positive mood enhancement. Appetite, 54, 143-149.

Van der Horst, K., Brunner, T. A., \& Siegrist, M. (2011). Ready-meal consumption: associations with weight status and cooking skills. Public Health Nutrition, 14(2), 239245.

Wallston, B. S., Wallston, K. A., Kaplan, G. D.., \& Maides, S. A. (1976). Development and validation of the Health Locus of Control (HLC) Scale. Journal of Consulting and Clinical Psychology, 44(4), 580-585.

Wallston, B. S., \& Wallston, K. A. (1978a).
Locus of control and health: A review of the literature. Health Education Monographs, 6(1), 107-117.

Wallston, K. A., \& Wallston, B. S. (1978b). Development of the Multidimensional Health Locus of Control (MHLC) Scales. Health Education Monographs, 6(2), 160-170.

Wallston, K. A. (1991). The importance of placing measures of health locus of control beliefs in a theoretical context. Health Education Research, 6(2), 251-252.

Winefield H.R., Winefield A.H., Tiggeman M. and Goldney R.D. (1989). Psychological concomitants of tobacco and alcohol use in young Australian adults. British Journal of Addiction, 84, 1067-1073.

Wong, K. K. K. (2013). Partial Least Squares Structural Equation Modeling (PLS-SEM) Techniques Using SmartPLS. Marketing Bulletin, 24, 1-32.

Yana, A. G. A., Rusdhi, H. A., \& Wibowo, M. A. (2015). Analysis of factors affecting design changes in construction project with Partial Least Square (PLS). Procedia Engineering, 125, 40-45. 


\section{$\langle$ Appendix〉}

〈Appendix A〉 Internal consistency and convergent validity of the RTH meals group

\begin{tabular}{cccccc}
\hline Item & Loading & Mean & SD & CR & AVE \\
\hline IHLC2 & 0.7398 & 4.03 & 0.81 & 0.8372 & 0.723 \\
\hline IHLC6 & 0.948 & 3.89 & 0.78 & & 0.8324 \\
\hline PHLC3 & 0.8545 & 2.95 & 0.9 & & 0.7129 \\
\hline PHLC5 & 0.8341 & 2.72 & 0.79 & 0.7878 & 0.5534 \\
\hline CHLC2 & 0.722 & 2.94 & 0.77 & & \\
\hline CHLC4 & 0.7326 & 2.41 & 0.8 & 0.8827 & \\
\hline CHLC6 & 0.776 & 2.42 & 0.98 & & \\
\hline GF1 & 0.7783 & 2.45 & 0.88 & & \\
\hline GF2 & 0.8029 & 2.11 & 0.9 & & \\
\hline GF3 & 0.8376 & 1.85 & 0.86 & & \\
\hline GF4 & 0.8125 & 2.92 & 0.98 & & \\
\hline WTB1 & 0.9041 & 3.53 & 0.88 & & \\
\hline WTB2 & 0.8964 & 3.5 & 0.85 & & \\
\hline WTB3 & 0.8813 & 3.08 & 0.84 & & \\
\hline
\end{tabular}

〈Appendix B〉 Internal consistency and convergent validity of the RTC meals group

\begin{tabular}{cccccc}
\hline Item & Loading & Mean & SD & CR & AVE \\
\hline IHLC1 & 0.7245 & 3.53 & 0.94 & 0.8723 & 0.5782 \\
\hline IHLC2 & 0.7792 & 4.11 & 0.76 & & \\
\hline IHLC4 & 0.8255 & 3.91 & 0.80 & & \\
\hline IHLC5 & 0.702 & 3.52 & 0.95 & & 0.6837 \\
\hline IHLC6 & 0.7647 & 3.89 & 0.77 & & \\
\hline PHLC2 & 0.828 & 2.8 & 0.98 & 0.8121 & \\
\hline PHLC5 & 0.8257 & 2.83 & 0.90 & & \\
\hline CHLC2 & 0.8286 & 3.13 & 0.89 & & \\
\hline CHLC3 & 0.7943 & 2.78 & 1.03 & & \\
\hline CHLC6 & 0.7266 & 2.65 & 1.05 & & \\
\hline GF1 & 0.848 & 2.29 & 0.85 & & \\
\hline GF2 & 0.8396 & 2.3 & 1.08 & & \\
\hline GF3 & 0.8747 & 1.92 & 0.92 & & \\
\hline GF4 & 0.781 & 2.77 & 0.99 & & \\
\hline WTB1 & 0.9015 & 3.66 & 0.81 & & \\
\hline WTB2 & 0.8759 & 3.7 & 0.84 & & \\
\hline WTB3 & 0.7698 & 3.22 & 0.82 & & \\
\hline
\end{tabular}

